\title{
The Methodology of Interactive Parametric Modelling of Construction Site Facilities in BIM Environment
}

\author{
Mária Kozlovská, Jozef Čabala, Zuzana Struková \\ Technical University of Košice \\ Faculty of Civil Engineering, Institute of Construction Technology and Management \\ e-mail: maria.kozlovska@tuke.sk,jozef.cabala@tuke.sk, zuzana.strukova@tuke.sk
}

\begin{abstract}
Information technology is becoming a strong tool in different industries, including construction. The recent trend of buildings designing is leading up to creation of the most comprehensive virtual building model (Building Information Model) in order to solve all the problems relating to the project as early as in the designing phase. Building information modelling is a new way of approaching to the design of building projects documentation. Currently, the building site layout as a part of the building design documents has a very little support in the BIM environment. Recently, the research of designing the construction process conditions has centred on improvement of general practice in planning and on new approaches to construction site layout planning. The state of art in field of designing the construction process conditions indicated an unexplored problem related to connection of knowledge system with construction site facilities (CSF) layout through interactive modelling. The goal of the paper is to present the methodology for execution of 3D construction site facility allocation model (3D CSF-IAM), based on principles of parametric and interactive modelling.
\end{abstract}

Key words: construction site layout, construction site facility, BIM model, parametric modelling, interactive modelling

\section{Introduction}

Nowadays, the information and digital technologies offer unprecedented possibilities useful in construction projects designing and managing. According to Wallbank [1], the radical change occurred at the beginning of the new millennium, when new 3D designing system with digital Building Information Model (BIM) as its root, appeared in digital design principles and practices. The term Building Information Model first appeared in a 1992 paper by Van Nederveen and Tolman [2], however the Autodesk company presented its digital form in 2002. The digital model consists of virtual equivalents of actual building parts and facilities unavoidable for construction, including construction site temporary facilities. Due to a certain amount of intelligence, the BIM is able to recognize the shape and action of structures in order to simulate the real action of buildings and parts of structures in real time. The BIM 
covers the areas of geometry, spatial relations, geographic information, numbers and properties of building components.

Building information modelling is a new way of approaching to the design of building projects documentation. Currently, the building site layout as a part of the building design documents has a very little support in the BIM environment.

When creating the variants of model construction site layouts, the adoption of parametric modelling is useful. Nowadays, the parametric modelling belongs in advanced and dynamically developing methods. One of advantages of these systems consists in fast generating the alternative possibilities of production space layout in order to choose the suitable one. Using the connection of 3D modelling and parametric modelling is possible to plan more effectively the construction site layout.

The 3D parametric modelling presents the base of information modelling of building structures. The parametric modelling is originated in 1980 in production industry. The parameters are understood as the geometry rules and some non-geometry properties and functions. The attributes, relating to other objects, may be the parameters. It allows the automatic update of objects following the other structures. Recently, the parametric modelling is classified as an advanced and dynamically developing method. In order to be applicable in the model creation, the parametric modelling must be based on existing or documented data. According to Kováč and Pečovská [3] main advantages of software systems, using the parametric modelling include automatic detection of links among entities, possible using of non-dimensional and dimensional parameters, simple selection of models from database following the hierarchy, graphical visualisation and group principle or possible creation of customer dialog boxes. Mallasi [4] noticed that the parametric decision-making system, when comparing with other systems, uses the geometric expressions to describe the relations and restrictions among objects.

In order to apply the system of 3D parametric modelling in construction site layout planning, it is necessary to analyze the topology of construction site facilities, thus the parameters of spatial design of site operation, its object models and relations among them. Experimenting with created models is possible to do more comprehensive and dynamic assessment of functional activity, systems behaviour and to solve necessary application tasks. A set of complex functional relations and links is developed. The range of spatial parameters of several construction site facilities, defining possibilities and constraints of their using, represents the key role. Using the 3D systems functions may be enhanced by creating the interactive connection of construction site parameters (automatic refusal of inconvenient construction site layout, identification of suitable construction site layout, etc.). However, the interactivity execution requires for well-considered and difficult modelling methodology from combination point of view.

Recently, the research of designing the construction process conditions has centred on improvement of general practice in planning and on new approaches to construction site layout planning. Several models of construction site have been developed. From construction site layout planning point of view, the models can be divided into static and dynamic [5]. The static models of construction site layout have been presented by various planning methods and tools, as knowledge systems [6], computer simulation [7], hybrid systems [8] and genetic algorithms [9 and 10]. The models of static construction site layout generate elementary 
production planning; it must be revised in case of some change. The dynamic models are in the second category from construction site layout planning point of view. The models provide for relocating the temporary site facilities in connection with variable spatial necessity. The construction time is divided into phases in dependence on being dynamic planning of construction site model. The construction site layout is planned chronologically for each construction phase. The dynamic models of construction site layout have been presented by various planning methods and tools, as genetic algorithms [11] for optimization of construction site layout in several construction phases, aimed at minimization of transport distance among selected temporary facilities. The optimal construction site layout from cost of site layout point of view can be found by the optimizing model of Osman et al. [12]. The hybrid model [13], employs optimization of temporary facilities based on restrictive conditions and linear programming in order to minimize the cost of transport and manipulation. At first, the temporary facilities are placed upon the set of heuristic regulations and then are lay on the basis of geometrical bonds among them.

Other studies [14] of construction site layout planning are based on knowledge systems and mathematical methods. The knowledge systems are used for designation of regulations helpful in construction site layout. The mathematical methods involve identification of one or more goals that determine the optimal site layout. They are based on mathematic models. It is mathematical programming for optimisation problems solving (e.g. determination of optimal solution following the entered criteria and entered constraints respecting). These include methods as parametric programming, dynamic programming, linear programming, non-linear programming, stochastic programming etc. The goal is mainly to minimize the cost of resources transport in the site and to optimize the site layout in compliance with specific constraints, resulting from construction process. In the Figure 1, there is also the system of interactive modelling the construction site facilities allocation, which employs the parametric properties of 3D models.

The state of art in field of designing the construction process conditions indicated an unexplored problem related to connection of knowledge system with construction site facilities (CSF) layout through interactive modelling.

\section{The methodology of interactive parametric modelling of spatial allocation of the CSF}

Methodology of interactive parametric modelling of spatial allocation of the CSF assumes that the building is designed through BIM technology. According to conception of 3D Construction Site Facility Interactive Allocation Model (3D CSF-IAM) methodology, presented in the Figure 1, it was necessary to prepare:

i) the library of construction site facilities models

ii) the subsystem for parametric modelling

iii) the subsystem for interactive modelling 


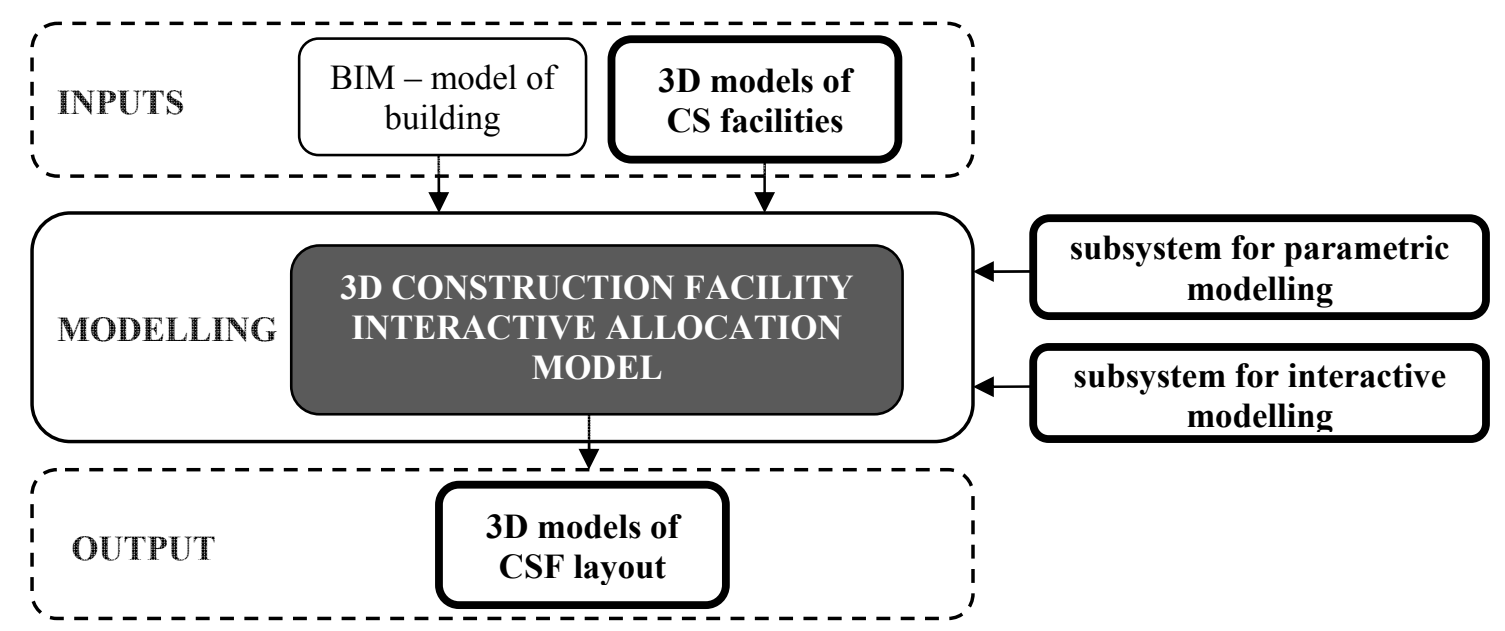

Figure 1: The conception of the methodology for creation of 3D Construction Site Facility Interactive Allocation Model

\subsection{Creation of digital database of construction site facilities models}

When creating any virtual model, for its easier and faster creation is necessary do have a library (database) of 3D models of objects which in virtual environment represent the digital model of existing object (equipment, product, material etc.). Recently, when creating a construction site layout plan in virtual environment, any 3D models of construction site facilities are normally available. Therefore, in order to use the possibilities of actual software technologies for construction site layout planning in 3D it is necessary to create the digital library of 3D models of construction site facilities.

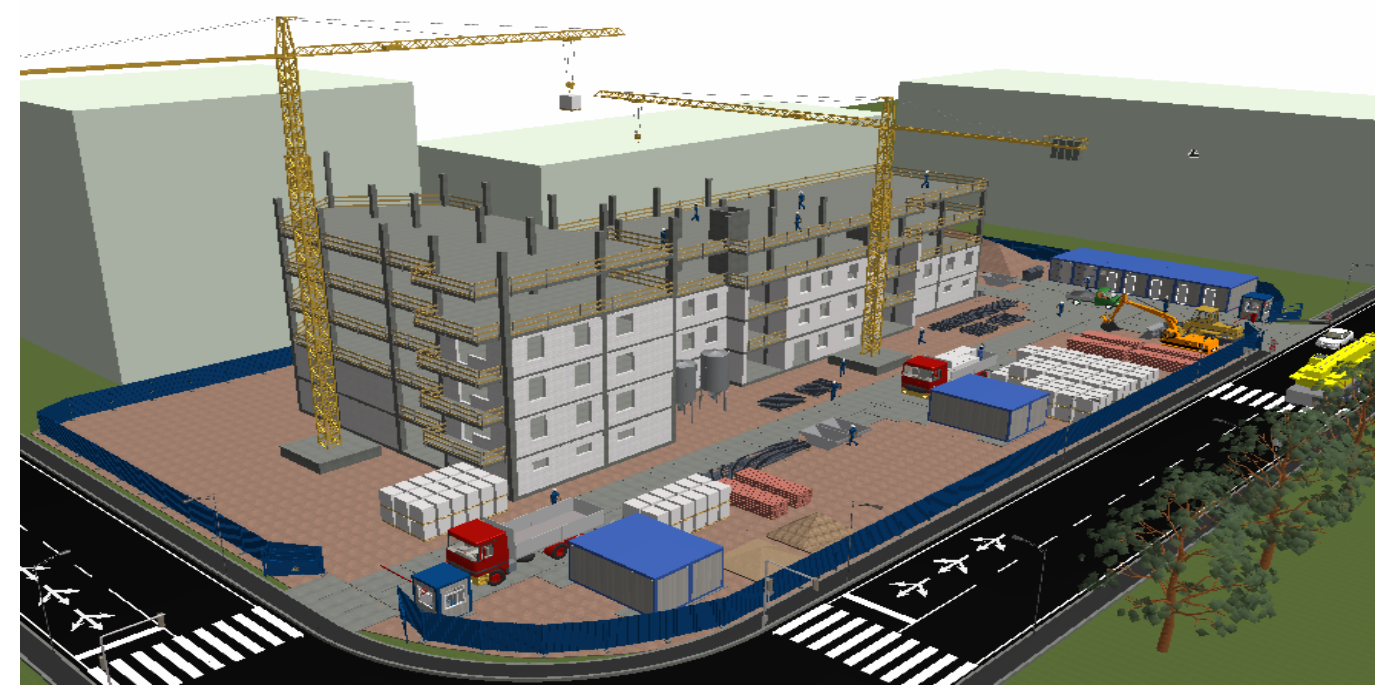

Figure 2: Possibilities of recent software technologies usable for construction site layout planning in 3D 
The composition of the proposed library containing the 3D models of construction site facilities is based on well-known classification of construction site facilities by their purpose. Following the classification, the main groups of CSF are defined as operating, production and social. According to Makýš and Jarský [15 and 16] the groups are then divided into subgroups. It is not sufficient for selection of a real model of CSF from software database. In order to create a 3D model is necessary to have the detailed list of CSF models in suitable arrangement. Therefore, it was important to answer which CSF from well-known classification could remain in original composition and which should be modified. The proposed composition of the library is characterized by the line: CSF groups - CSF subgroups - CFS - object models of CSF. The library has been created in ArchiCAD (Figure 3).

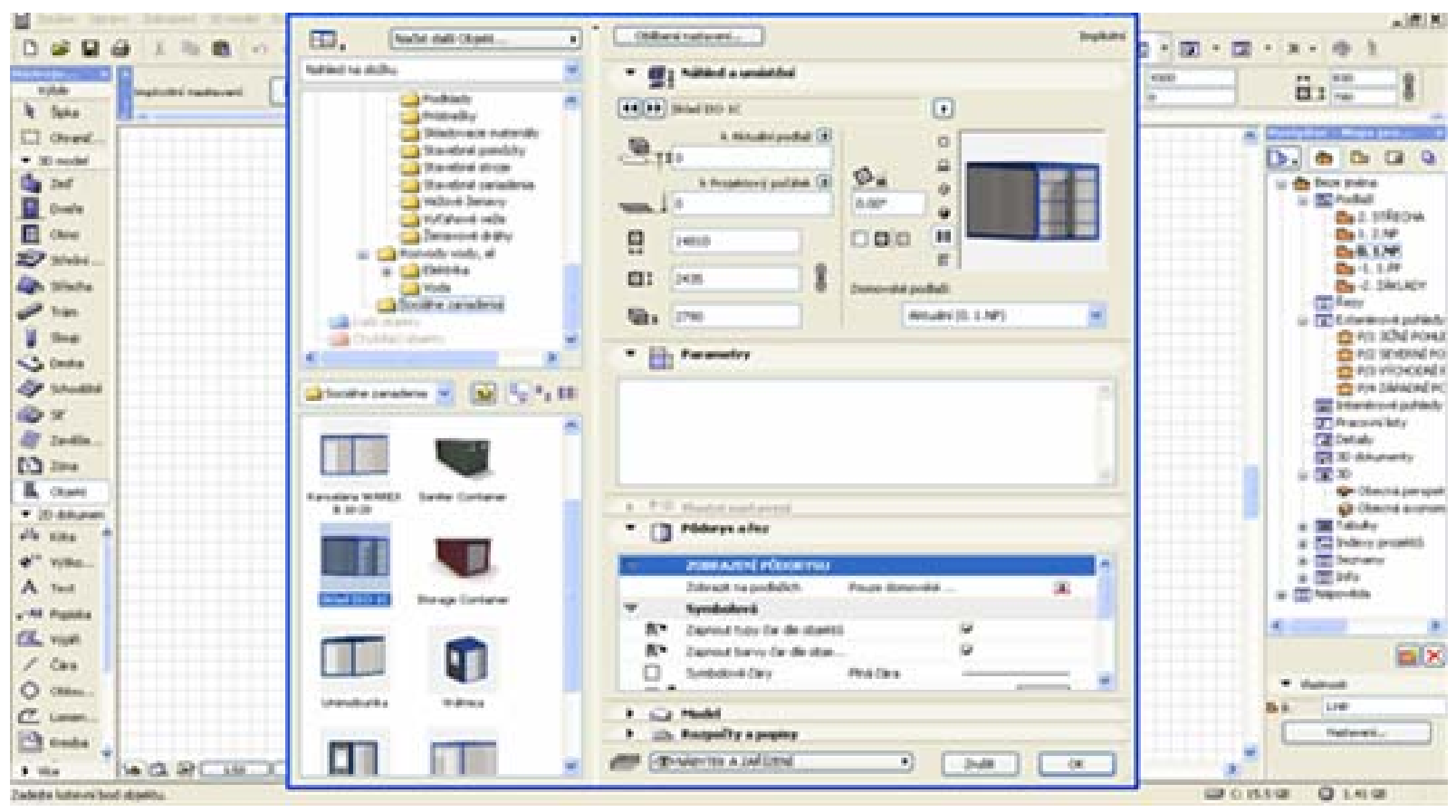

Figure 3: The digital library of CSF models in ArchiCAD

\subsection{The three-dimensional parametric modelling}

Using three-dimensional and parametric modelling creates the possibility for more efficient processing of project documentation. Experimentation with established 3D models allow complex and dynamically evaluate the functional activity behaviour of systems and to solve the necessary application tasks. In the creation model variants proposals of CSF is appropriate to use parametric modelling, which is now inserted between advanced and dynamically developing methods.

Parametric modelling tools help to optimize the model feasibility of projects and ensure that projects meet established goals. The concept of parametric modelling is derived from the project parameters that are modified during the project simulation process. Parametric models are built from a set of mathematical equations. Parametric models that had any validity must 
be based on actual or established project data. Parametric methods are very useful for early exposure of 3D models an uncertain situation or active pitfalls. They conveniently include a lot of previous experience and are less misstatement than the actual human thinking processes. The main advantages of software systems using parametric modelling can include [3]:

- The simplicity of parametric models creation.

- The possibility of using dimensional and not dimensional parameters.

- Automatic detection of links between entities and eliminate unnecessary links.

- Principle of variants nesting allows the creation of complex models.

- Simplicity of model selection from the database based on a hierarchy, graphical visualization and the principle of group.

- Modify the database structure,

- The possibility of custom dialog boxes creation.

- Use a wide range.

- The possibility of further development.

The parametric modelling may be considered to be the method resulting from the link between modelling and drawings and in software systems has in all respects the potential for effective 3D modelling of construction site operation. When creating the spatial model of construction site operation, the parametric modelling provides:

- allocating the construction site facilities with respect to spatial constraints of the site,

- respecting the site configuration and division on the basis of geometrical natures of site forms and dimensions and on the basis of links among construction site facilities,

- optimising the site area occupation on the basis of dimensions and location of storing places, preparation places, production places etc.,

- optimising the selection of assembling equipments in the context of constructed building and site conditions,

- detection of occupational safety risks and consistent coordination of construction works with respect to occupational safety and health,

- information on impact of the construction process on surrounding environment, on people participating and non-participating the construction,

- information on construction site model relative to its measure, cost, mounting, operation and dismantling,

- better identification of risks connected with the site operation in each construction phase.

Each from construction site facilities may be geometrically specified as a unit with some form (geometry) and measure and its locating in the site depends on surrounding spatial interactions. The geometric properties of construction site facilities models represent the spatial physical object (volume body). It is possible to generate the geometrical objects, to define and add new interaction parameters that create possibilities and constraints of site facilities allocation. It is possible to define the groups of geometrical forms (modules) of construction site facilities as well as define their dependencies. The dependencies are expressed by parameters.

The mathematical expression of object space " $\mathrm{O}_{(\mathrm{i})}$ " of mobile container and operating space of object "OsO $\mathrm{O}_{(\mathrm{i})}$ " of mobile container, as well as mathematical expression of the module of mobile containers together with its operating space "OsM" is presented in Table 1. 
Table 1: Mathematical expression of parameters of 3D model of containers module

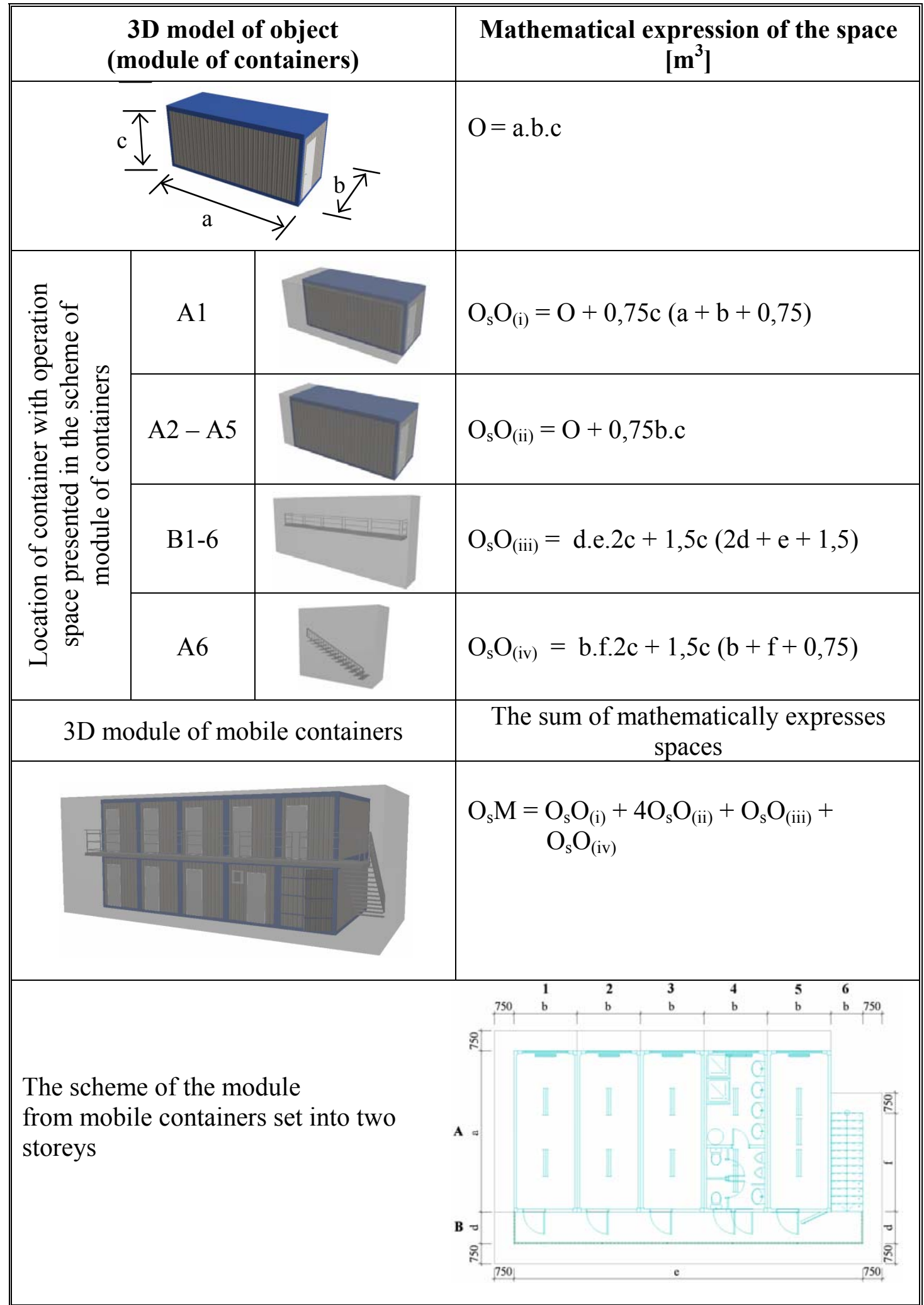




\subsection{The system of interactive parametric modelling of building site}

In the system is possible to define the main elements, represented by object models and their interactions. The decomposition of the system into elements and their characters knowledge create assumes for interventions into structure of the system. The interventions eventuate in improving the elements functions and thus into improving the function of the system as a whole. Within the proposal of the system of interactive parametric modelling of building site, the main elements include construction site facilities (construction site objects) expressed together with operating space of the object (Figure 4). The operating space retires the minimal/maximal space of construction site facilities (construction site objects), necessary for the object functionality performance.

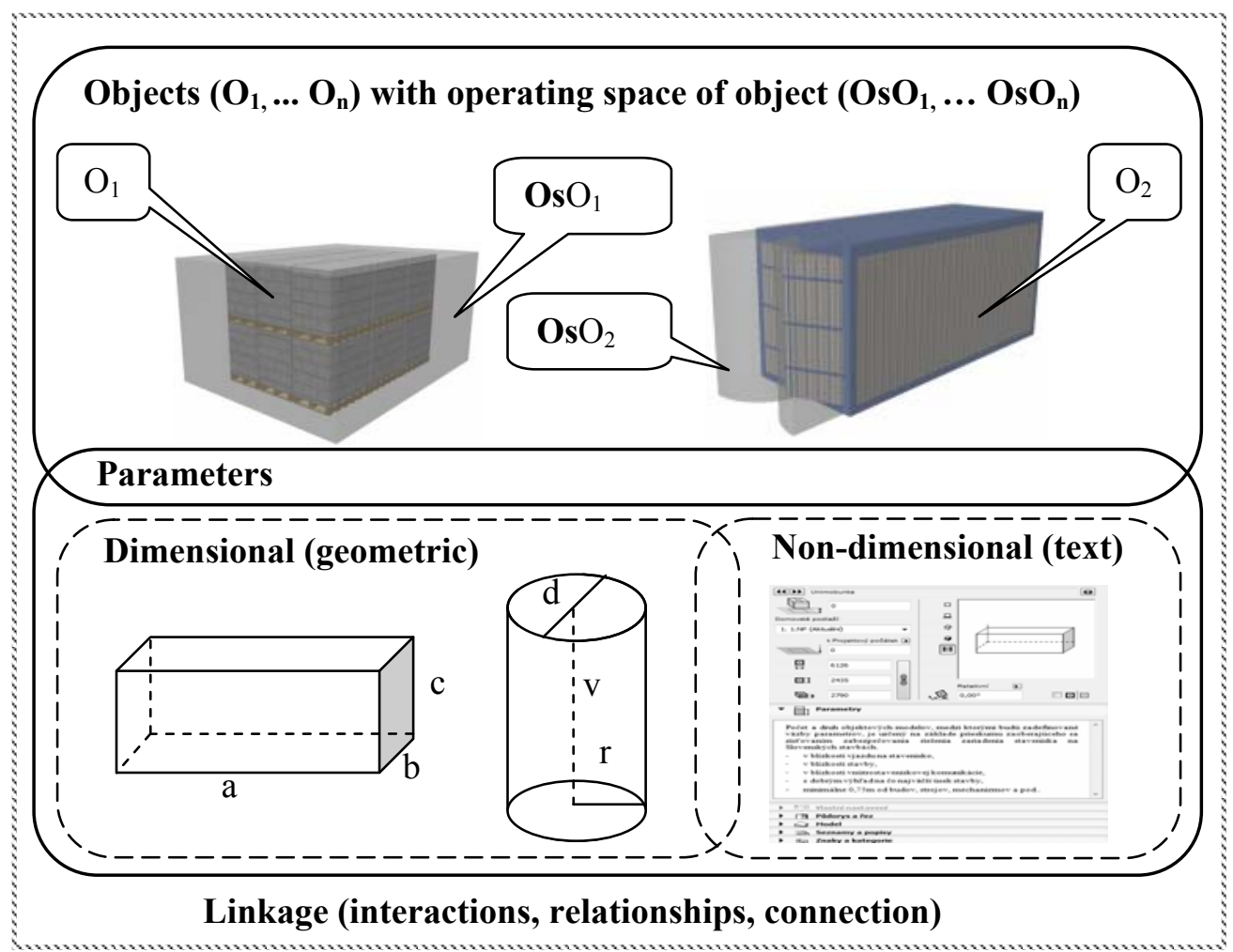

Figure 4: System for exploring the spatial (geometrical and text) parameters of CSF objects

The text information about conditions and principles of facility allocation in the site are used for specification of indirect interaction (indirect parameters) among facility models in the site. The information, useful for author of construction site layout model, can be displayed in software systems by dialog box of facility induced from selection of the facility model from library. Based on implementation of direct and indirect parameters in software systems, the allocation of 3D construction site facilities models in the site model is supported by knowledge decision making. The colour indication of allocated model of construction site facility, automatically signalizing the right or wrong allocation of the facility, serves as supporting function in interactive construction site layout planning. In the Figure 5 is 
presented the model of the system of interactive parametric modelling of building site. It integrates the before mentioned sub-systems for modelling of allocating the CSF in 3D model of the site.

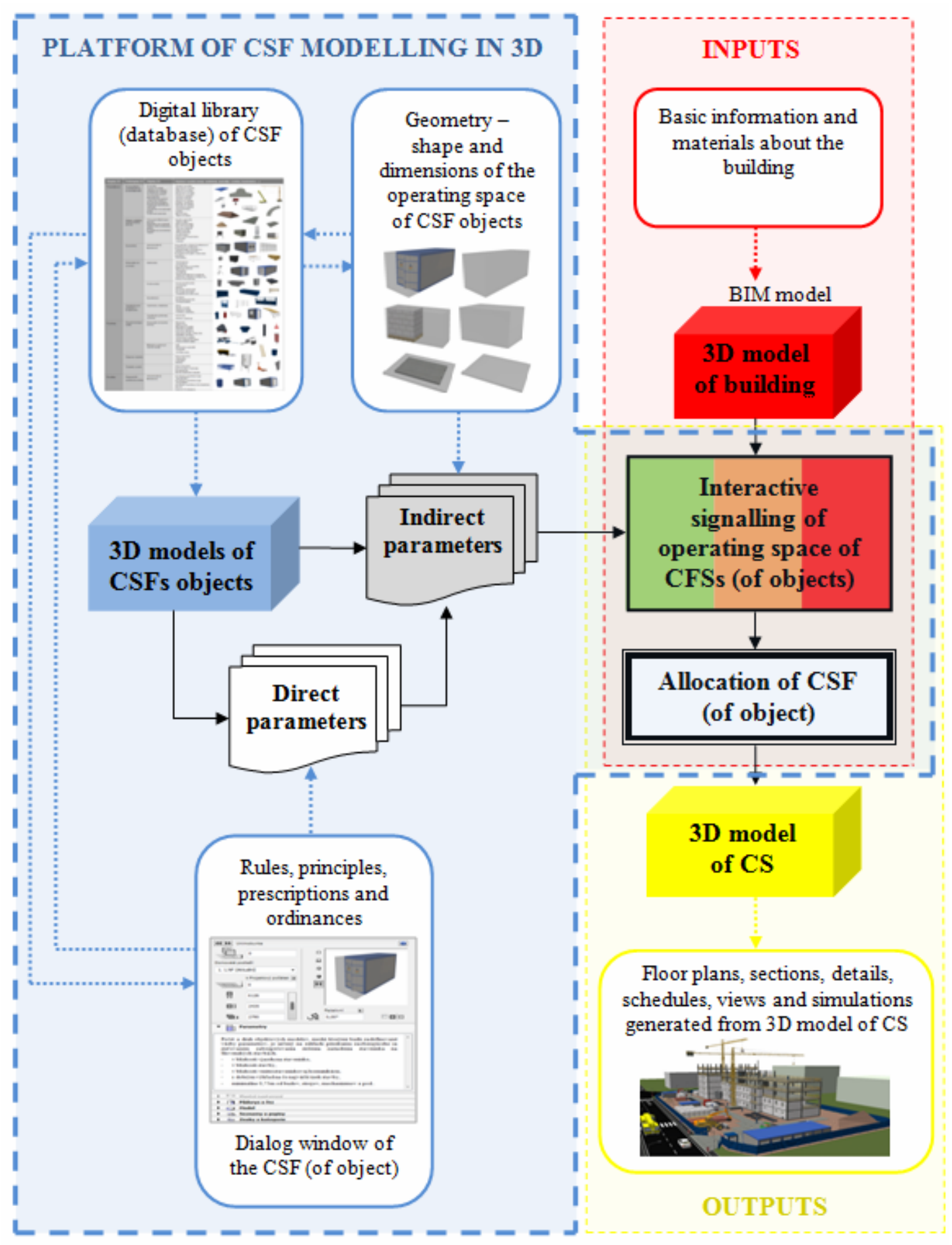

Figure 5: The model of system of spatial allocation of CSFs objects in a 3D model of CS 
In order to identify the possible spatial allocation of construction site facility automatically and interactively, the operating space of allocated facility model is indicated by colours (Figure 6). The colour indication of allocated facilities uses:

- green colour, if facility allocation is not restricted by any other facilities (including its operating extent), the facility may be allocated in this place,

- orange colour, if facility allocation is influenced by collision of operating space of the facility with operating space of other facility or with other facility, eventually with buildings in the site; contingent suitability of facility allocation should be considered (from sufficient operating space point of view) and space conflicts with other facilities should be eliminated in regard of facility`s necessary functionality.

- red colour, if facility allocation is restricted by other object, another suitable position of the facility should be found.

\begin{tabular}{|c|c|c|}
\hline $\begin{array}{c}\text { Suitable allocation } \\
\text { (green colour) }\end{array}$ & $\begin{array}{c}\text { Suitable allocation with } \\
\text { restriction (orange colour) }\end{array}$ & $\begin{array}{c}\text { Unsuitable allocation } \\
\text { (red colour) }\end{array}$ \\
\hline & & \\
\hline
\end{tabular}

Figure 6: Virtual presentation of colour signals of allocated object

The full application of the proposed methodology may be found in the software systems supporting 3D modelling based on BIM. In order to integrate the methodology into the systems, it is unavoidable to have knowledge related to these systems programming whereas the functions for "sophisticated" solution of interactive identifying the spatial allocation of construction site facility must be integrated into software.

In order to perform this activity, the programmers from companies as CADexpert, ŠTOR CAD Computers, BIMsoft etc. were requested to cooperate. After consultations with specialist from CADexpert and ŠTOR CAD Computers, all requested persons agreed with the following solution. The proposed methodology application, specifically related to function of interactive colour signalization of allocated construction site facility in 3D software environment using BIM system, may be performed by API (Application Programming 
Interface) functionality. This function serves as an interface for applications programming, it specifies the set of functions and routines that perform certain tasks or allow creating the interactions with specific software components in software engineering.

\section{Conclusion}

The methodology of interactive parametric modelling of construction site facilities is based on research of different construction site facilities typology and on mathematical clarifying of their connections in order to objectification of the construction site occupation while maintaining all requirements for modelling of operational and production conditions of construction works organization. Such expression of construction site facilities forms a support for creation of interactive parametric environment supported by virtual modelling of spatial allocation of construction site facilities in 3D construction site model and using BIM system. The development of the methodology depended on:

- suggestion of the composition and processing the digital library of 3D models of construction site facilities which could be completed by other information,

- defining the file of direct (geometrical) and indirect (text information) parameters of 3D models of construction site facilities, on which the spatial allocation depends,

- suggestion of the concept of 3D Construction Site Facility Interactive Allocation Model (3D CSF-IAM) methodology,

- suggestion of algorithm for aggregating the construction site facilities through function of interactive colour signalization of allocated object in 3D software environment that uses BIM.

The result of the research has proved the potential of BIM for spatial planning of construction site conditions, what allows for better communications among all construction project participants.

\section{Acknowledgements}

The paper is the result of the Projects implementation: Excellent integrated research centre of progressive building construction, material and technology, ITMS: 26220120037 and University Science Park TECHNICOM for Innovation Applications Supported by Knowledge Technology, ITMS: 26220220182, supported by the Research \& Development Operational Programme funded by the ERDF.

\section{References}

[1] Wallbank, B. (2014-04-09). Virtual Building concept. Available at: http://www.graphisoft.com/products/virtual_building/

[2] Van Nederveen, G.A., Tolman, F.P. (1992). Modelling multiple views on buildings. Automation in Construction. Vol. 1 (3), p. 215-224. DOI: 10.1016/0926-5805(92)90014-B.

[3] Kováč, J. \& Pečovská, K. (2002). Parametrické modelovanie montážnych prostriedkov a systémov. Available at: http://www.sjf.tuke.sk/transferinovacii/ pages/archiv/transfer/52002/pdf/147-150.pdf. 
[4] Mallasi, Z. (2014-04-24). Identification, and visualisation of construction activities' workspace conflicts utilising $4 D \quad C A D / V R$ tools. Available at: http://www.iconviz.com/downloads/pub/Mallasi-ASCAAD2005-pap.pdf

[5] Khaled, E.R. \& Hisham, S. (2009). Dynamic Site Layout Planning Using Approximate Dynamic Programming. Journal of Computing in Civil Engineering. Vol. 23 (2), p. 119-127. DOI: 10.1061/(ASCE)0887-3801(2009)23:2(119).

[6] Sadeghpour, F., Moselhi, O. \& Alkass, S.T. (2006). Computer-aided site layout planning. Journal of Construction Engineering and Management. Vol. 132 (2), p. 143 - 151. DOI: 10.1061/(ASCE)0733-9364(2006)132:2(143).

[7] Dawood, N. \& Marasini, R. (2003). Visualisation of a stockyard layout simulator "SimStock": a case study in precast concrete products industry. Automation in Construction. Vol. 12 (2), p. 113-122. DOI: 10.1016/S0926-5805(02)00044-4.

[8] Zhang, J.P., Liu, L.H. \& Coble, R.J. (2002). Hybrid intelligence utilization for construction site layout. Automation in Construction. Vol. 11 (5), p. 511-519. DOI: 10.1016/S09265805(01)00071-1.

[9] Cheung, S.O., Kin-Lun Tong, T. \& Tam, Ch.M. (2002). Site pre-cast yard layout arrangement through genetic algorithms. Automation in Construction. Vol. 11 (1), p. 35-46. DOI: 10.1016/S0926-5805(01)00044-9.

[10] Tam, C., Tong, T. \& Chan, W. (2001) Genetic Algorithm for Optimizing Supply Locations around Tower Crane. Journal of Construction Engineering and Management. Vol. 127 (4), p. 315-321. DOI: 10.1061/(ASCE)0733-9364(2001)127:4(315).

[11] Elbeltagi, E., Hegazy, T. \& Eldosouky, A. (2004). Dynamic Layout of Construction Temporary Facilities Considering Safety. Journal of Construction Engineering and Management. Vol. 130 (4), p. 534-541. DOI: 10.1061/(ASCE)0733-9364(2004)130:4(534).

[12] Osman, H., Georgy, M. \& Ibrahim, M.E. (2003). An automated system for dynamic construction site layout planning. In $10^{\text {th }}$ International Colloquium on Structural and Geotechnical Engineering, April 22-24 (p. 1-13). Cairo, Egypt: Ain Shams University.

[13] Zouein, P. \& Tommelein, I. (1999). Dynamic Layout Planning Using a Hybrid Incremental Solution Method. Journal of Construction Engineering and Management. Vol. 125 (6), p. 400408. DOI: 10.1061/(ASCE)0733-9364(1999)125:6(400).

[14] Hesham, M.O., Georgy, M.E. \& Ibrahim, M.E. (2003). A hybrid CAD-based construction site layout planning system using genetic algorithms. Automation in Construction. Vol. 12 (6), p. 749-764. DOI: $10.1016 / \mathrm{S} 0926-5805(03) 00058-\mathrm{X}$

[15] Makýš O., Makýš P. (2003). Stavenisková prevádzka, zariadenie staveniska. Bratislava: STU Bratislava.

[16] Jarský, Č., Musil, F., Svoboda, P., Lízal, P., Motyčka, V. \& Černý, J. (2003). Technologie staveb II - Príprava a realizace staveb. Brno: CERM Akademické nakladatelství s.r.o. 